\title{
Tobacco Use among Health Professional Students in Chitwan, Nepal
}

\author{
Niki Shrestha, ${ }^{1}$ Sanjeeb Shah, ${ }^{2}$ Gayatri Khanal, ${ }^{1}$ Suneel Piryani ${ }^{1}$ \\ 'Department of Public Health and Community Medicine, Chitwan Medical College, Bharatpur, Chitwan, \\ ${ }^{2}$ Triveni Technical Academy, Itahari-4, Sunsari, Nepal.
}

\begin{abstract}
Background: Health professional students play a critical role in tobacco control by providing services, advocating for policies and serving as role models for social change. This study aimed to estimate the prevalence of tobacco use and determine the attitude and behavior regarding tobacco use among health professional students.

Methods: A cross-sectional study was conducted among third-year medical, dental, nursing and pharmacy undergraduates using GHPSS questionnaire.

Results: A total of $16.3 \%$ students were current cigarette smokers. 33.2\% students had ever smoked cigarettes, and $57.0 \%$ had smoked first cigarettes during adolescence life. Cigarette smoking consumption was higher than the use of other tobacco products like chewing tobacco, snuff, bidis, hookah, cigar or pipes and. $10.0 \%$ students were current users of other tobacco products. $22.1 \%$ students had ever used other tobacco products. $31.6 \%$ were exposed to second-hand smoke at home and $48.9 \%$ were exposed to second-hand smoke at public places.

Conclusions: The prevalence of smoking and exposure to second-hand was high among medical students. Medical educators should consider revising the medical curricula to focus on tobacco cessation training/counseling in medical schools.

Keywords: GHPSS; health professional; Nepal;tobacco.
\end{abstract}

\section{INTRODUCTION}

The use of tobacco is globally, a major public health problem. ${ }^{1}$ Tobacco is a preventable cause of premature deaths and non-communicable diseases. ${ }^{1}$ Each year nearly six million people globally, die from tobaccorelated diseases. ${ }^{1,2}$ An additional 600,000 deaths occur from exposure to second-hand smoke. ${ }^{1,2}$ By 2030 , this number is expected to exceed 8 million deaths and $70 \%$ of these deaths will occur in developing countries. ${ }^{1}$

Health professionals and health professions students can impart a vital role in tobacco control by delivering effective medical intervention against tobacco use. However, despite the crucial role of health professional students in tobacco control, very few studies have collected information regarding use of tobacco, training to provide cessation counseling, and exposure to second-hand smoke among health professions students. This study was conducted to find out the prevalence of tobacco use and to know the attitudes and behavior regarding tobacco use among health professions students.

\section{METHODS}

A cross-sectional study was conducted among all thirdyear undergraduates of medicine, dentistry, nursing and pharmacy of Chitwan Medical College (CMC) Nepal, in July 2015. Out of 200 students enrolled in the third year, 190 students participated in the study and the nonresponse rate was $5 \%$. The responses of 190 students (105 medicine, 48 dentistry, 29 nursing and 8 pharmacy students) were included in the study.

The Global Health Professional Students Survey (GHPSS) questionnaire, was used in this study, which was developed by the World Health Organization (WHO), the US Centers for Disease Control and Prevention (CDC) and the Canadian Public Health Association. This study was a school-based survey of third-year students pursuing advanced degrees in dentistry, medicine, nursing and pharmacy. The anonymous, selfadministered questionnaire comprised of core questions on demographics, prevalence of cigarette smoking and other tobacco use, knowledge of and attitude towards tobacco use, exposure to secondhand smoke, desire 
for smoking cessation, and training received regarding patient counseling on smoking cessation techniques.

Questionnaire was administered during regular class sessions in an anonymous, voluntary manner, according to the protocol. The questionnaire was pretested among 20 undergraduates of third-year medicine in another medical college to ensure that the students could understand and answer the questions without any help. The validity of the questions was established by using standard questionnaire, which has been used in many previous studies across the world. Questionnaire was distributed to the participants by a single investigator and the questionnaire was collected on the same day. Descriptive (frequencies and percentage)and bivariate (chi-square test) were performed using the SPSS version 21 software. Statistical significance was considered at $\mathrm{p}$-value $<0.05$.

Verbal informed and written consent was taken from the participants. The participants were also informed that their participation in the study was completely voluntary and that they had the right to withdraw from participation at any time, for any reason before data collection. Confidentiality of the information assured. Ethical approval for the study was taken from the institutional review committee of Chitwan Medical College.

The current smokers were defined as those who smoked cigarettes daily or occasionally during the past 30 days preceding the survey. The non-smokers were defined as those who never ever smoked a cigarette in their lifetime. The ever smokers were defined as those who had smoked even a single cigarette in their lifetime. Other tobacco products were defined as products such as chewing tobacco, snuff, bidis, hookah, cigar or pipes.

\section{RESULTS}

Out of 190 students, 93 (48.9\%) were male, and 97 $(51.1 \%)$ were female. The mean $( \pm$ SD) age of the participants was $21.39( \pm 1.39)$ years.

A total of $16.3 \%$ students were current cigarettes smokers. One-third of them had smoked cigarettes ever (33.2\%), and the majority of them (57.0\%) had smoked their first cigarette during their adolescence life (11-19 years). One of every ten students $(10.0 \%)$ currently used other tobacco products like chewing tobacco, snuff, bidis, hookah, cigar or pipes and around $1 / 4^{\text {th }}$ students (22.1\%) had ever used other tobacco products (Table1).

Around one-third of the students (31.6\%) were exposed to second-hand smoke at home, while half of the students (48.9\%) at public places during the past week preceding the survey (Table2).

Compared to current smokers, non-smokers were statistically significantly more positive in putting ban tobacco sale to adolescents $(74.2 \%$ vs. $90.6 \%$, p-value 0.030); banning tobacco advertisement $(48.4 \%$ vs. $73.0 \%$, p-value 0.007); banning smoking in restaurants ( $29.0 \%$ vs. $66.7 \%$, p-value $<0.001)$, banning smoking in disco/bars/pubs (12.9\% vs. $44.7 \%$, p-value 0.001$)$, and banning smoking in enclosed public places $(77.4 \%$ vs. 93.1\%, p-value 0.014)(Table 3).

There was no statistically significant difference between current smokers and non-smokers regarding the perception about the necessity for specific training on cessation techniques for health professionals $(87.1 \%$ vs. 91.2\%, p-value 0.502 ). Similarly, there was no statically significant difference between current smokers and non-smokers regarding the view on health professionals serving as "role models" for their patients and the general population ( $77.4 \%$ vs. $88.7 \%$, p-value 0.141$)$. However, a statistically significant difference was observed between current smokers and non-smokers concerning their views on whether health professionals should routinely give advice on quitting smoking and other tobacco products (87.1\% vs. $96.9 \%$, p-value 0.041 ). Likewise, a statistically significant difference was found between current smokers and non-smokers in believing that the chance of smoking cessation would increase with advice from health professionals ( $86.8 \%$ vs. $67.7 \%$, p-value 0.009$)$. Moreover, no statistically significant difference was seen in the responses from current smokers and non-smokers regarding their views on whether health professionals who smoke are less likely to advise patients to stop smoking (58.1\% vs. $71.8 \%$, p-value 0.132$)$. Similarly, no statistically significant difference was seen in the responses from current smokers and non-smokers regarding their views on whether health professionals who use other tobacco products are less likely to advise patients to stop smoking ( $51.6 \%$ vs. $68.6 \%$, p-value 0.069$)$ (Table3).

Majority of the students (94.2\%) mentioned that dangers of smoking were taught during class. Likewise, most of the students $(85.3 \%)$ were taught about the reasons why people smoke. Similarly, the majority of the participants $(94.7 \%)$ had learned about the importance of tobacco use history. Around $4 / 5$ th of students $(81.1 \%)$ had learned that it is important to provide educational quitting materials regarding quitting to support smoking cessation to patients who want to quit smoking. Whereas, only $20.5 \%$ of the students had ever received 
the formal training on smoking cessation. Regarding knowledge about smoking cessation methods, three out of every five students $(60.5 \%)$ were aware of nicotine replacement therapies, and $1 / 3$ rd of the students (33.2\%) were aware of the use of antidepressants. No statistically significant difference was observed between current smokers' and non-smokers' responses regarding anti-tobacco education and smoking cessation training in the medical school curriculum (Table 4).

\section{Table 1. Prevalence of tobacco use.}

Characteristics

Male $(\mathrm{n}=93) \quad$ Female $(\mathrm{n}=97) \quad$ Total $(\mathrm{N}=190)$

1. Ever tried/experimented with cigarette smoking

Yes

No

2. Respondent's age when s/he first tried cigarette

$\leq 10$ years

11 - 19 years

$\geq 20$ years

3. Currently smoking cigarette

Yes

No

4. Ever tried other tobacco products*

Yes

No

5. Currently using other tobacco products*

Yes

No

No. (\%)

No. (\%)

No. (\%)

$50(79.4)$

43 (33.9)

13 (20.6)

63 (33.2)

84 (66.1)

127 (66.8)

10 (66.7)

5 (33.3)

15 (23.8)

$29(80.6$

7 (19.4)

36 (57.0)

11 (91.7)

1 (8.3)

12 (19.2)

$30(96.8)$

1 (3.2)

31 (16.3)

63 (39.6)

$96(60.4)$

159 (83.7)

32 (76.2)

10 (23.8)

42 (22.1)

61 (41.2)

87 (58.8)

148 (77.9)

17 (89.5)

2 (10.5)

19 (10.0)

76 (44.4)

95 (55.6)

$171(90.0)$

\section{Table 2. Exposure to tobacco smoke.}

\section{Characteristics}

Male $(n=93)$

No. (\%)

Female $(n=97)$

Total $(\mathrm{N}=190)$

1. Exposure to tobacco smoke at home during past week

$\begin{array}{llll}\text { Yes } & 46(76.7) & 14(23.3) & 60(31.6) \\ \text { No } & 47(36.2) & 83(63.8) & 130(68.4)\end{array}$

2. Exposure to tobacco smoke at public places during past week

Yes

60 (64.5)

33 (35.5)

93 (48.9)

No

33 (34.0)

64 (66.0)

97 (51.1)

Table 3. Medical students' attitudes towards tobacco control policies and smoking cessation.

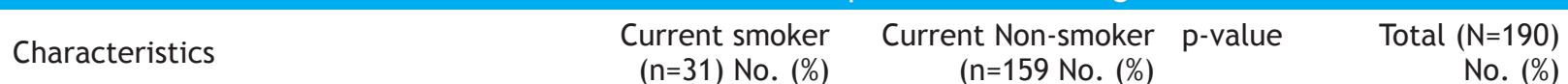

1. Should tobacco sale to adolescents be banned?

\begin{tabular}{|rrrr|r|}
\hline Yes & $23(74.2)$ & $144(90.6)$ & $0.030^{*}$ & $167(87.9) 23$ \\
\hline No & $8(25.8)$ & $15(9.4)$ & $(12.1)$
\end{tabular}

2. Should advertising of tobacco products be completely banned?

\begin{tabular}{|lrr|r|r|}
\hline Yes & $15(48.4)$ & $116(73.0)$ & $0.007^{*}$ & $131(68.9) 59$ \\
\hline No & $16(51.6)$ & $43(27.0)$ & $(31.1)$ \\
\hline
\end{tabular}

3. Should smoking be banned in restaurants?

\begin{tabular}{rrrr|r|} 
Yes & $9(29.0)$ & $106(66.7)$ & $<0.001^{*}$ & $115(60.5) 75$ \\
\hline No & $22(71.0)$ & $53(33.3)$ & $(39.5)$
\end{tabular}


4. Should smoking be banned in disco/bars/pubs?

\begin{tabular}{rrrr|r|} 
Yes & $4(12.9)$ & $71(44.7)$ & $0.001^{*}$ & $75(39.5)$ \\
\hline No & $27(87.1)$ & $88(55.3)$ & $115(60.5)$
\end{tabular}

5. Should smoking in all enclosed public place be banned?

$\begin{array}{lrrrr}\text { Yes } & 24(77.4) & 148(93.1) & 0.014^{*} & 172(90.5) \\ \text { No } & 7(22.6) & 11(6.9) & 18(9.5)\end{array}$

6. Should health professionals get specific training on cessation techniques?

\begin{tabular}{rrrrr|} 
Yes & $27(87.1)$ & $145(91.2)$ & 0.502 & $172(90.5)$ \\
\hline No & $4(12.9)$ & $14(8.8)$ & $18(9.5)$
\end{tabular}

7. Do health professionals serve as "role models" for their patients and the public?

\begin{tabular}{|rrrrr|}
\hline Yes & $24(77.4)$ & $141(88.7)$ & 0.141 & $165(86.8)$ \\
\hline No & $7(22.6)$ & $18(11.3)$ & $25(13.2)$
\end{tabular}

8. Should health professionals routinely give advice on quitting smoking?

\begin{tabular}{|c|c|c|c|c|}
\hline Yes & $27(87.1)$ & $154(96.9)$ & $0.041^{*}$ & $181(95.3)$ \\
\hline No & $4(12.9)$ & $5(3.1)$ & & \\
\hline
\end{tabular}

9. Should health professionals routinely give advice on quitting other tobacco products?

\begin{tabular}{rrrr|r} 
Yes & $27(87.1)$ & $154(96.9)$ & $0.041^{*}$ & $181(95.3)$ \\
No & $4(12.9)$ & $5(3.1)$ & $9(4.7)$
\end{tabular}

10. Do health professionals have role in giving advice about smoking cessation?

\begin{tabular}{|c|c|c|c|c|}
\hline Yes & $28(90.3)$ & $157(98.7)$ & $0.031^{*}$ & $185(97.4)$ \\
\hline No & $3(9.7)$ & $2(1.3)$ & & $5(2.6)$ \\
\hline \multicolumn{3}{|c|}{ Do chance of quitting smoking increases if health professional gives advice? } & $0.009^{*}$ & \\
\hline Yes & $21(67.7)$ & $138(86.8)$ & & $159(83.7)$ \\
\hline No & $10(32.3)$ & $21(13.2)$ & & $31(16.3)$ \\
\hline
\end{tabular}

12. Are health professionals who smoke less likely to advise patient to stop smoking?

\begin{tabular}{|c|c|c|c|c|}
\hline Yes & $18(58.1)$ & $114(71.8)$ & 1 & $132(69.5)$ \\
\hline No & 13 (41.9) & $45(28.3)$ & & $58(30.5)$ \\
\hline
\end{tabular}

13. Are health professionals who use tobacco product (e.g. chewing tobacco, snuff, bidis hookah, cigar or pipes) less likely to advise patient to stop smoking?

\begin{tabular}{|c|c|c|c|c|}
\hline Yes & $16(51.6)$ & $109(68.6)$ & 9 & $125(65.8)$ \\
\hline No & $15(48.4)$ & $50(31.4)$ & & $65(34.2)$ \\
\hline
\end{tabular}

"p-value $<0.05$

Table 4. Medical school curriculum on tobacco cessation.

Characteristics

$\begin{array}{rrrr}\begin{array}{r}\text { Current } \\ \text { ( }(\mathrm{n}=31)\end{array} & \begin{array}{r}\text { Total } \\ (\mathrm{N}=190)\end{array} \\ \text { No. }(\%) & \text { No. }(\%) & \text { No. }(\%)\end{array}$

1. During class were taught about danger of smoking

$\begin{array}{lrrrr}\text { Yes } & 29(93.5) & 150(94.3) & 1.000 & 179(94.2) \\ \text { No } & 2(6.5) & 9(5.7) & 11(5.8)\end{array}$

2. During class were taught about the reason why people smoke

\begin{tabular}{|c|c|c|c|c|}
\hline Yes & $25(80.6)$ & $137(86.2)$ & 0.414 & $162(85.3)$ \\
\hline No & $6(19.4)$ & $22(13.8)$ & & $28(14.7)$ \\
\hline \multicolumn{5}{|c|}{ Learnt that it is important to record tobacco use history } \\
\hline Yes & $28(90.3)$ & $152(95.6)$ & 0.211 & $180(94.7)$ \\
\hline
\end{tabular}


Tobacco Use among Health Professional Students

\begin{tabular}{|c|c|c|c|c|}
\hline No & $3(9.7)$ & $7(4.4)$ & & $10(5.3)$ \\
\hline \multicolumn{5}{|c|}{ 4. Ever received formal training on smoking cessation } \\
\hline Yes & $7(22.6)$ & $32(20.1)$ & 0.757 & $39(20.5)$ \\
\hline No & $24(77.4)$ & $127(79.9)$ & & $151(79.5)$ \\
\hline
\end{tabular}

5. Learnt that it is important to provide educational quitting materials

\begin{tabular}{|c|c|c|c|c|}
\hline Yes & $28(90.3)$ & $126(79.2)$ & 0.211 & $154(81.1)$ \\
\hline No & $3(9.7)$ & $33(20.8)$ & & $36(18.9)$ \\
\hline \multicolumn{5}{|c|}{ 6. Ever heard of nicotine replacement therapies } \\
\hline Yes & $21(67.7)$ & $94(59.1)$ & 0.369 & $115(60.5)$ \\
\hline No & $10(32.3)$ & $65(40.9)$ & & $75(39.5)$ \\
\hline \multicolumn{5}{|c|}{ 7. Heard of antidepressant use in tobacco cessation program } \\
\hline Yes & $11(35.5)$ & $52(32.7)$ & 0.764 & $63(33.2)$ \\
\hline No & $20(64.5)$ & $107(67.3)$ & & $127(66.8)$ \\
\hline
\end{tabular}

\section{DISCUSSION}

Tobacco smoking is considered as one of the most important preventable risk factors for chronic diseases. Paradoxically, health professionals, while identifying tobacco smoking as the essential preventable cause of mortality and morbidity, are not aware of their primary role to support people quit tobacco smoking. In some countries, the prevalence of tobacco smoking among health professionals and health profession students is higher than among the general population.

In this study, the prevalence of current tobacco smoking was found to be $16.3 \%$. This prevalence rate is lower than the general population (37\%) and higher than the 15-19 years old adolescents (13.1\%) at the national level. ${ }^{3}$ This prevalence rate is also higher than the study conducted in India in 2013 (9\%) and lower than the studies conducted in European 2011 (29\%), Italy in 2013 (38.2\%), Greece in 2011 (33\%). . $^{-7}$ This rate was also lower than reported in a study conducted among nurses of 39 countries and Gaza strip (20\%). ${ }^{8}$ Tobacco use endangers the health of health professions students and negatively affects the future health professionals' credibility to deliver effective anti-tobacco counseling when they start managing the patients. The prevalence of ever smokers in this study was $33.2 \%$ which was much lower than reported by multicenter Italian survey (64.1\%), studies conducted in University of Malta Europe (65.9\%), Catania University Medical Schools Italy (77.5\%), and Greece (74\%). ${ }^{6,7,9,10}$

The prevalence of ever smokers and the prevalence of current smokers could have been affected by several factors such as the socio-cultural milieu, tobacco control legislation, policies and programmes, status of tobacco production, tobacco import and export as well as issues related to the taxation on tobacco products.

The present study showed that $57.0 \%$ students had smoked their first cigarettes during their adolescence life (11-19 years) which is higher than the study conducted in Europe, in 2011 (34.4\%). ${ }^{5} \mathrm{~A}$ high percentage of smoking prevalence among Nepalese adolescents may be because of aggressive marketing of tobacco products targeted at adolescents by the tobacco companies and weak enforcement of tobacco control legislation for purchasing of tobacco products by adolescents and selling them.

This study found that $1 / 4^{\text {th }}$ of the students were exposed to smoking below the age of 10 years, which shows that early exposure to tobacco smoking is very high. The socio-cultural setting in Nepal is such that Nepalese parents ask their children to fetch cigarettes for them and even to light up the cigarettes for them particularly in rural areas so that these children also eventually take up smoking at a very early age. Such early exposure leads to adverse health consequences in the long run. This study found that the lifetime prevalence and current prevalence of cigarette smoking is higher than the lifetime prevalence and current prevalence of use of other tobacco products. A similar pattern was found in different studies. ${ }^{4,7,11}$ It may be due to the fact that tobacco advertisement and marketing is more focused on smoking forms of tobacco rather than on other forms of tobacco products.

This study found that $86.8 \%$ students believed that health professionals are role models for patients. Studies conducted in Europe(2011) and Catania University Medical Schools Italy (2013), found that twothirds and more than half of medical students believed that health professionals are role models for patients, 
respectively..$^{6,11}$

A vast majority $(95.3 \%)$ of the students in this study believe that health professionals should routinely give advice on quitting other tobacco products. This finding was similar to the findings of a study conducted in Catania University Medical Schools Italy (96\%). ${ }^{6}$

A total of $83.7 \%$ students in this study believe that chance of smoking cessation would increase with advice from health professionals. This finding is consistent with the findings of the study from Catania University Medical Schools Italy where $82.5 \%$ students believe that chance of smoking cessation would increase with advice from health professionals. ${ }^{6} \mathrm{~A}$ study from Europe also showed that a high percentage of Spanish and Polish students believed the same. ${ }^{5}$

This study showed that $97.4 \%$ students believed that health professionals have a role in giving advice about smoking cessation. This finding is much higher than the findings reported by multicenter Italian survey where only $65 \%$ students believed that health professionals have a role in giving advice about smoking cessation. ${ }^{9}$ The students (future health practitioners) who accord little importance to physicians' advice are unlikely to make an effort to do counseling for smoking-prevention once they become general practitioners.

In the present study, $90.5 \%$ health professionals opined that they should get specific training on cessation techniques. This finding is compatible with the findings of the study conducted in Catania University Medical Schools Italy(94.3\%) and reported by multicenter Italian survey (87.7\%), ${ }^{6,9}$ Whereas this is higher than reported in a study from India, 84.3\%. ${ }^{4}$ Present study found that only $20.5 \%$ students had ever received formal training on smoking cessation. This finding is consistent with the finding of the study conducted in Catania University Medical Schools Italy(21.3\%). ${ }^{6}$ But inconsistent with the findings reported by a study from Europe (16.5\%), multicenter Italian survey (10.6\%)and Indian study(8.5\%). 4,5,9 Though a high percentage of medical students in this study opine that they should get specific training on tobacco cessation techniques, in reality, very few of them receive the formal training on tobacco cessation. Health professionals who continue to smoke, send the inconsistent message to patients whom they counsel, and need to acquire knowledge about smoking-related diseases and specific skills in smoking cessation techniques. A smoking health professional will have a significant impact on the smoking habits of their patients/clients in the general population. Hence, tobacco cessation training to future health professionals is essential. Health Professions students are believed to be the medical practitioners of the future need to acquire knowledge about smoking-related diseases and specific skills in smoking cessation techniques. Teaching medical students how to help smokers to quit smoking is an important issue that has to be incorporated into the curricula of medical schools. ${ }^{12-15}$

This study has certain methodological limitations. First, this study was cross-sectional, so this study only postulates a snapshot of the situation. Second, smoking status of the participants was assessed through selfreport, rendering this study results comparably less reliable. Lastly, the findings of this study are difficult to generalize as this study was conducted only in one medical college of Nepal.

\section{CONCLUSIONS}

This study concluded that the prevalence of smoking was high among health professions undergraduates. Medical Educational stakeholders should discourage tobacco use among health professions undergraduates' students. All health professionals should work jointly to plan and implement programs that provide training on effective cessation- counseling techniques to health professions undergraduates students by using evidence-based approaches. Rules and regulations related to tobacco should be made stringent in the country.

\section{REFERENCES}

1. World Health Organization. MPOWER: A policy package to reverse the tobacco epidemic. Geneva: World Health Organization; 2008.[Full Text]

2. World Health Organization. World Report on the Global Tobacco Epidemic, 2009: Implementing Smoke free Environments. Geneva: World Health Organization, 2009. [Full Text]

3. MoHP, New ERA, and ICF International Inc. Nepal Demographic and Health Survey 2011. Ministry of Health and Population, New ERA, and ICF International, Calverton, Maryland: Kathmandu, Nepal; 2012.[Full Text]

4. Shailee F, Girish MS, Vikas F, Bharat B, Baljeet S, Praveen D, Arun ST. Knowledge of, attitude towards, and prevalence of tobacco use among dental students in Himanchal Pradesh State, India. Unpublished.

5. Torre LG, Kirchi W, Rastrolllo BM, Ramos MR, Czaplicki M, GualanoRM, Thummler K, et, at. Tobacco use among Medical students in Europe: Results of a multicenter study using the Global Health Professions students survey. Public Health. 2012; 126:159-164.[PubMed] 
6. Ferrante M, Saulle R, Ledda C, Pappalardo R, Fallico R, Torre LG, Fiore M. Prevalence of Smoking habits, attitudes, knowledge and beliefs among Health Professional School Students: a cross - sectional study. Ann Ist Super Sanita. 2013; 49(2):143-149. [Full Text]

7. Evridiki P, Constantine IV, Penelope N, Charles WM, Anastasis B, Jenny K, Gregory NC, et, al,. Nursing education and beliefs towards tobacco cessation and control: a cross - sectional national survey (GHPSS) among nursing students in Greece. Tabacco Induced Disease. 2011; 9(4):1-6. [Full Text]

8. Warren WC, Sinha ND, Lee J, Lea V, Jones RN. Tobacco use, Exposure to Secondhand Smoke, and Training on CessationalCounselling among Nursing Students: CrossCountry Data from Global Health Profession Students Survey, 2009. Int. J Environ Res Public Health. 2009; 6:2534-2549.[Full Text]

9. Saulle R, Bontempi C, Baldo V, Boccia G, Bonaccorsi G, Busaferro S, Donato F, et al,.GHPSSMulticentre Italian Survey: smoking prevalence, knowledge and attitudes, and tobacco cessation training among third-year Medical students. Tumori. 2013; 99:17-22. [PubMed]

10. Cauchi D, Mamo J. Smoking Health professionals Student: An Attitudinal Challenge for Health Promotion?. Int J Environ Res Public Health. 2012; 9:2550-2561.[Full Text]
11. SreemareddyTC, Suri S, Menezes GR, HarshaKHN, Rahman M, Islam RMD, Pereira VX. Self-reported tobacco smoking practices among Medical Students and their perceptions towards training about tobacco smoking in Medical Curricula: A cross-Sectional, questionnaire survey in Malaysia, India, Pakistan, Nepal and Bangladesh. Substance Abuse Treatment Prevention and Policy. 2010; 5(29):1-9.[Full Text]

12. Chatkin J, Chatkin G. Learning about smoking during medical school: are we still missing opportunities? Int J Tuberc Lung Dis. 2009; 13: 429e37.[Full Text]

13. Spanish Health and Social Politics Ministry. European Health Survey in Spain. 2009. [Full Text]

14. Thyrian JR, Panagiotakos DB, Polychronopoulos E, West $\mathrm{R}$, ZantonskiW, John U. The relationship between smokers' motivation to quit and intensity of tobacco control at the population level: a comparison of five European countries. BMC Public Health. 2008; 8:2.[Full Text]

15. GTSS Collaborative Group. Tabacco use and cessation counseling: Global Health Professionals Survey Pilot Study, 10 countries, 2005. Tob Control. 2006; 15(Suppl.2): ii31e34.[Full Text] 